\title{
FÓRUNS DE DISCUSSÃO ON-LINE: USO DA TAXIONOMIA DE BLOOM
}

\author{
Fábio Luiz da Silva* - Unopar
}

Palavras-chave: Ação Pedagógica. Tecnologias. Ensino.

\section{INTRODUÇÃO}

É consenso que o uso dos computadores foi uma das maiores transformações ocorridas nos últimos 150 anos no campo das tecnologias de comunicação. A disseminação de todo tipo de computador pessoal, combinada com a emergência da internet, afetou toda a vida em sociedade. Mudaram as formas como trabalhamos, como nos comunicamos e como nos divertirmos. Essas transformações criaram enormes oportunidades de aprendizagem (GARRISON; ANDERSON, 2003). Assim, os cursos que se utilizam de ferramentas e recursos on-line podem suprir grande parte da necessidade de aprendizagem existente na sociedade.

No entanto, segundo Luhrs e McAnally-Salas (2016), apesar do número crescente de cursos mediados por computadores, o conhecimento de como se realiza a aprendizagem com apoio tecnológico ainda é escasso e fragmentado. $\mathrm{O}$ mesmo poderíamos afirmar do ensino realizado por meio de recursos on-line. Uma das dificuldades nesse sentido é a transição do ensino presencial para o ensino online, fenômeno sentido por inúmeros professores, pois exige deles a reconstrução de suas crenças e atitudes sobre o ensino e sobre a aprendizagem em ambientes online (BARAN; CORREIA, 2014). Uma das principais diferenças, pelo menos a princípio, entre o ensino presencial e o on-line é a possibilidade da discussão, da troca de ideias, do estímulo ao debate que pode existir em uma sala de aula presencial. A possibilidade de interação entre o professor e os alunos é considerada de grande importância, especialmente no ensino superior.

A existência de chats e fóruns de discussão na estrutura dos cursos mediados pelos computadores demonstra o esforço em garantir que a interação exista mesmo quando professores e alunos estão fisicamente distantes. Segundo Bai (2009), a 
discussão on-line é uma estratégia importante para a comunicação na educação a distância. No entanto, apesar desse potencial, a qualidade real das discussões nem sempre é satisfatória. Considerando que o envolvimento cognitivo dos alunos é uma preocupação constante dos professores, diversos estudos têm demonstrado que as postagens em fóruns de discussão consistem, em sua maioria, de comparação e compartilhamento de informações, partilha de experiências pessoais e oferecimento de opiniões pessoais superficiais. Em outras palavras, há pouca evidência de discussão aprofundada, baseada em pensamento crítico.

Ertmer et al (2007) consideram que o diálogo promove a aprendizagem entre aqueles que participam de uma comunidade, seja ela on-line ou face a face. No entanto, também afirmam que as discussões estudantis geralmente giram em torno de histórias pessoais ou de conteúdo descritivo. Por isso, há a necessidade de compreender melhor como as discussões nos fóruns contribuem, ou melhor, como podem contribuir, para os objetivos do ensino. Para alguns pesquisadores, embora haja potencial nesses fóruns para melhorar a reflexão, a qualidade dessa reflexão é muitas vezes superficial. Frequentemente os alunos não discordam das participações dos colegas e/ou seus argumentos são de qualidade muito baixa (NUSSBAUM et al, 2002).

Por isso a necessidade de realizar-se mais pesquisas sobre o ensino on-line, em especial a respeito do fórum de discussão, pois esse é um dos recursos mais importantes para a construção do pensamento crítico entre os alunos que participam de cursos à distância. Se for possível encontrar meios de aperfeiçoar essa metodologia, pode-se contribuir para a melhora da qualidade do ensino e da aprendizagem mediada pelos computadores. Por isso o objetivo desse artigo é apresentar a possibilidade da utilização da taxionomia de Bloom como recurso metodológico para o desenvolvimento de fóruns de discussão on-line mais efetivos.

\section{DESENVOLVIMENTO}

\section{Ensino}

Em qualquer instituição educacional espera-se que os professores ensinem e os alunos aprendam. Essa expectativa, no entanto, envolve questões nada simples. Há inúmeras pesquisas sobre ensino e sobre aprendizagem, todas elas fundamentadas em pressupostos teóricos mais ou menos divergentes. No caso do ensino, Gómez (1998) apresenta quatro enfoques para compreendê-lo. Ensino como 
transmissão cultural: o ensino é entendido como transmissão do conhecimento produzido e acumulado pela humanidade às novas gerações; Ensino como treinamento de habilidades: o ensino é compreendido como treinamento de habilidades e capacidades; Ensino como fomento do desenvolvimento natural: o ensino é visto como a facilitação do desenvolvimento natural, que deve ser dirigido por suas próprias regras; e Ensino como produção de mudanças conceituais: o ensino é compreendido como estímulo às transformações do pensamento e das crenças dos estudantes.

Gómez (1998) aponta as limitações de cada uma dessas perspectivas. No caso da transmissão cultural, o ensino pode ser reduzido à memorização descontextualizada do conteúdo. O treinamento de habilidades tende a desconsiderar a importância dos conteúdos na determinação das habilidades e competências. O enfoque do desenvolvimento natural é frágil em seu idealismo que ignora as condicionantes históricas, sociais e culturais que agem sobre os indivíduos. Por fim, a produção de mudanças conceituais também parece desprezar a importância chave dos conteúdos para a cultura. Diante disso, Gómez (1998, p. 70) afirma

\footnotetext{
[...] pode-se considerar o ensino como um processo que facilita a transformação permanente do pensamento, das atitudes e dos comportamentos dos alunos/as, provocando a comparação de suas aquisições mais ou menos espontâneas em sua vida cotidiana com as proposições das disciplinas científicas, artísticas e especulativas, e também estimulando sua experimentação na realidade.
}

Essa definição, parece-nos, evita as principais limitações das perspectivas anteriormente citadas e absorve aquilo que é útil de cada uma delas. O ensino objetiva a constante transformação do pensamento, das atitudes e do comportamento dos alunos, pois estimula a comparação entre o senso comum e o conhecimento científico, artístico e filosófico, bem como a ação na realidade. Nesse caso, conteúdos, habilidades e competências são entendidos como elementos interligados e não excludentes na atividade do ensino.

\section{Fórum de discussão on-line}

Na educação à distância, o ensino é realizado por meio de diversos recursos tecnológicos que, à primeira vista, parecem substituir as práticas presenciais dos professores. É assim que as teleaulas ou vídeoaulas substituiriam a aula expositiva 
do professor e o fórum de discussão faria as vezes da interação professor/aluno em sala de aula. Tal substituição, no entanto, não é plena, pois o uso de recursos e processos tecnológicos diferentes requerem uma compreensão de suas características particulares. Assim, um fórum de discussão on-line é diferente de uma discussão face a face, em sala de aula. A diferença mais evidente é a mudança da oralidade típica da aula presencial para a leitura e escrita na modalidade on-line. A comunicação oral exige códigos diferentes daqueles utilizados na escrita. Enquanto a primeira é mais flexível, a segunda pauta-se por normas mais rígidas. Essa diferença, no entanto, não implica em um problema. Apenas temos de reconhecê-la.

A importância do fórum de discussão como recurso pedagógico no ensino online foi reconhecida em diversos estudos: Luhrs e McAnally-Salas (2016), Silva (2015), Bai (2009), Ertmer et al (2007), Swan et al (2007), Nussbaum et al (2002), entre outros. Silva (2015) define fórum como sendo "um recurso que permite a comunicação entre alunos, professores e tutores em AVAs, auxiliando na elucidação de dúvidas, na expressão de opiniões, na discussão de tópicos e na reflexão sobre os conceitos debatidos" (p. 27). Uma das características desse recurso é a não simultaneidade da comunicação, ou seja, a comunicação é assíncrona. Para Azevedo, Behar e Reategui (2012), as interações proporcionadas pelos fóruns de discussão fornecem momentos de reflexão sobre os conteúdos estudados e a capacidade de refletir é fundamental para qualquer aluno.

\section{Pensamento crítico}

A transformação do pensamento, que se realiza por meio da reflexão, tem ligação direta com o conceito de pensamento crítico, o qual, nas palavras de Veiga et al, engloba, dentro de um vasto campo de definições, contribuições da filosofia e da psicologia cognitiva. Nesse campo, as ações seguiriam uma orientação, incluindo as competências cognitivas

[...] que incluem a compreensão verbal, a análise de argumentos, a confirmação de hipóteses, a probabilidade e incerteza -, e a tomada de decisão e resolução de problemas - que pressupõe igualmente uma componente relacionada com a disposição para fazer uso dessas competências (HALPERN, 1998, 2003 apud VEIGA et al., 2016, p.111).

O pensamento crítico tem, portanto, relação com a prática da reflexão e a tomada de decisões de modo mais eficaz e produtivo, tanto no que diz respeito à 
vida cotidiana quanto ao campo das ideias e discussões teóricas. Porém, afirmar que os alunos devem ser capazes de refletir ou de pensar criticamente é praticamente senso comum e não deixa evidente o que significa ser um aluno reflexivo ou crítico. Rocha (2011) procurando tornar mais explícito o conceito de pensamento crítico afirma que "[...] existe um sem-número de definições que tentam circunscrever a natureza particular deste processo complexo do pensamento crítico" (p. 43). Entre as diversas possibilidades de definição desse conceito, Rocha (2011) afirma que, para Bloom, o pensamento crítico corresponderia aos três níveis superiores de sua taxionomia: análise, síntese e avaliação. Podemos ver as mesmas categorias de Bloom na seguinte definição de pensamento crítico:

[...] é o processo intelectualmente disciplinado de, ativamente e habilmente, conceituar, aplicar, analisar, sintetizar e/ou avaliar informações obtidas de, ou geradas por: observação, experiência, reflexão, raciocínio ou comunicação, como um guia para convicções e ações (SCRIVEN; PAUL apud PETRESS, 2004, p.3)

Assim, para Rocha (2011) essa definição articula os processos cognitivos, as fontes do conhecimento e os objetivos do ensino. É compreensivo, portanto, que Ekahitanond (2013) tenha utilizado a taxionomia de Bloom para avaliar a promoção do pensamento crítico por meio dos fóruns de discussão on-line.

\section{Taxionomia de Bloom}

O livro Taxonomy of Educational Objectives, obra de Bloom e outros quatro autores, foi publicado primeiramente em 1956. A taxionomia de Bloom tem sido, desde então, utilizada por professores de todas as áreas e em todos os níveis de ensino. O impacto das ideias de Bloom foi sentido com grande intensidade no campo da avaliação, pois a taxionomia de Bloom oferece uma poderosa ferramenta para a realização de avaliações baseadas em objetivos. Por isso, ela tem sido utilizada em avaliações em larga escala nos Estados Unidos desde a década de 1960 (MARZANO; KENDALL, 2007). No Brasil, o Exame Nacional de Desempenho de Estudantes (Enade), que avalia o rendimento dos concluintes dos cursos de graduação, utiliza a taxionomia de Bloom para aferir se os conteúdos programáticos, as habilidades e as competências foram adquiridas em sua formação.

Ferraz e Belhot (2010) apresentam duas vantagens na utilização da taxionomia de Bloom no contexto educacional. A primeira diz respeito ao desenvolvimento de 
instrumentos de avaliação úteis para estimular a melhora do desempenho dos alunos e a segunda refere-se à possibilidade dos professores auxiliarem os alunos, de forma estruturada e consciente, a adquirirem o conhecimento e as habilidades necessárias. Ekahitanond (2013) afirma que a taxionomia de Bloom pode ajudar os professores a identificar o nível cognitivo no qual os alunos são capazes de trabalhar.

Em sua forma original, a taxionomia de Bloom é apresentada na forma de seis níveis do processo cognitivo: conhecimento, compreensão, aplicação, análise, síntese e avaliação. Segundo Marzano e Kendall (2007), cada nível é definido por determinadas características, resumidamente descritas a seguir:

$\checkmark$ Conhecimento: é o nível da lembrança de conteúdos já aprendidos e que podem ser fatos, terminologias, convenções, critérios, princípios, teorias, entre outros.

$\checkmark$ Compreensão: é o nível da compreensão do conteúdo, isto é, da captação do seu significado e da sua utilização em contextos diversos.

$\checkmark$ Aplicação: é o nível da utilização dos conteúdos aprendidos em novas situações, ou seja, a aplicação de abstrações, princípios ou métodos em situações específicas.

$\checkmark$ Análise: é o nível da divisão do conteúdo em suas partes com o objetivo de compreendê-lo, ou seja, é necessário que a estrutura do conteúdo tenha sido entendida.

$\checkmark$ Síntese: é o nível da construção de um novo todo a partir de diversas partes, isto é, significa a geração de estruturas de conhecimento.

$\checkmark$ Avaliação: é o nível do julgamento a respeito do valor de determinado conhecimento, por meio de critérios internos ou externos.

A taxionomia de Bloom, pressupõe, portanto que exista uma hierarquia cognitiva. Segundo Ferraz e Belhot (2010), "todo desenvolvimento cognitivo deve seguir uma estrutura hierárquica para que, no momento oportuno, os discentes sejam capazes de aplicar e transferir [...] um conhecimento adquirido" (p. 431). Nesse caso, a taxionomia de Bloom pode colaborar como instrumento de classificação de objetivos, delimitação de conteúdos e confecção de instrumentos de avaliação. Mais importante, ela pode ser utilizada em qualquer modalidade de ensino, presencial ou à distância. 
A taxionomia de Bloom foi utilizada por muitos aos e foi revista no início do século XXI por um grupo de pesquisadores, entre os quais David Krathwohl, que havia colaborado com Bloom na construção da taxionomia original (FERRAZ; BELHOT, 2010). Essa revisão deu origem a uma nova taxionomia de Bloom, que geralmente é adjetivada com as expressões revisada ou atualizada. Pressupondo que essa nova taxionomia tenha incorporado os avanços científicos nos campos do ensino e da aprendizagem, optou-se pela sua utilização nessa pesquisa. A seguir é apresentada a taxionomia de Bloom revisada:

$\checkmark$ Lembrar: é o nível do reconhecimento e da reprodução dos conteúdos, isto é, da busca, distinção, seleção e reprodução de determinada informação; é representado pelos verbos: reconhecendo e reproduzindo.

$\checkmark$ Entender: é o nível do estabelecimento das conexões entre o conhecimento que já se possui e o novo conhecimento, ou seja, nesse nível o indivíduo deve ser capaz de reproduzir um conteúdo com suas próprias palavras; é representado pelos verbos: interpretando, exemplificando, classificando, resumindo, inferindo, comparando e explicando.

$\checkmark$ Aplicar: é o nível da execução ou uso do conhecimento em uma situação específica, isto é, da aplicação do conteúdo em uma nova situação; é representado pelos verbos: executando e implementando.

$\checkmark$ Analisar: é o nível da divisão da informação em partes de forma que seja possível: julgá-las como mais ou menos importantes e entender as relações entre essas partes; é representado pelos seguintes verbos: diferenciando, organizando, atribuindo e concluindo.

$\checkmark$ Avaliar: é o nível do julgamento baseado em critérios e padrões quantitativos ou qualitativos; é representado pelos verbos: checando e criticando.

$\checkmark$ Criar: é o nível da criação de novas soluções, estruturas, modelos ou visões pelo uso dos conhecimento e habilidades anteriormente adquiridos, ou seja, trata-se do desenvolvimento de ideias ou produtos novos e originais; é representado pelos verbos: generalizando, planejando e produzindo.

Essa nova taxionomia continua considerando que há uma hierarquia cognitiva, no entanto, ela tem a vantagem de tornar mais claro o que se espera de cada nível (KRATHWOHL, 2002). Outra diferença significativa foi a possibilidade da construção uma tabela bidimensional, na qual conhecimento e processo cognitivo são 
contemplados. O conhecimento está presente na dimensão vertical e divide-se em quatro níveis, segundo Krathwohl (2002):

$\checkmark$ Conhecimento factual: é o nível dos elementos básicos que um indivíduo deve saber para estar familiarizado com uma determinada disciplina e possa resolver questões a respeito dela; está vinculado ao conhecimento da terminologia e de elementos específicos da disciplina em questão.

$\checkmark$ Conhecimento conceitual: é o nível das inter-relações entre os elementos básicos em uma estrutura mais complexa; está vinculado ao conhecimento da classificação, categorias, princípios, generalizações, teorias, modelos e estruturas.

$\checkmark$ Conhecimento procedural: é o nível do como fazer algo utilizando métodos, técnicas e ferramentas; está vinculado ao conhecimento específico de habilidades, técnicas, métodos e de critérios para utilização de determinados procedimentos.

$\checkmark$ Conhecimento metacognitivo: é o nível ao reconhecimento da própria cognição em geral e da amplitude do conhecimento específico adquirido; está relacionado ao conhecimento estratégico, autoconhecimento e conhecimento contextual.

Na dimensão horizontal estão os níveis do processo cognitivo, já mencionados. Uma tabela construída com esses elementos ficaria como na Figura 1:

Figura 1: Tabela bidimensional da Taxionomia de Bloom Revisada

\begin{tabular}{|c|c|c|c|c|c|c|c|}
\hline \multirow{5}{*}{ 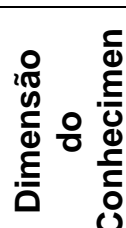 } & & \multicolumn{6}{|c|}{ Dimensão do Processo Cognitivo } \\
\hline & & Lembrar & Entender & Aplicar & Analisar & Avaliar & Criar \\
\hline & Factual & & & & & & \\
\hline & Conceitual & & & & & & \\
\hline & Procedural & & & & & & \\
\hline & Metacognitivo & & & & & & \\
\hline
\end{tabular}

Fonte: Adaptado de Krathwohl (2002).

Para Krathwohl (2002), ainda, essa taxionomia revisada tem a vantagem de não ser tão rígida quanto a original. Além disso, "a combinação das dimensões do processo de conhecimento e cognitivo cria uma tabela muito útil" (KRATHWOHL, 2002, p.218), que pode tornar claros os objetivos de um curso ou de uma unidade de conteúdo. Sua representação visual concisa facilita a tomada de decisão dos professores. 


\section{CONCLUSÃO}

Há estudos que apontam a possibilidade do uso da taxionomia de Bloom na pesquisa sobre fóruns de discussão on-line e que indicam o seu uso igualmente como instrumento útil para o planejamento, execução e avaliação de planos de ensino. Os fóruns de discussão on-line são mecanismos importantes para e educação a distância mediada pelas tecnologias de comunicação, pois é um momento potencial de diálogo. Para Knowlton (2001), a construção de um conhecimento durável - acrescentaríamos: e do pensamento crítico - não é obra do acaso em uma discussão on-line. Para superar a prática do "uso pelo uso" da tecnologia é preciso que professores e tutores explorem o recurso dos fóruns com fundamento teórico. É nesse sentido que apresentamos nesse artigo a possibilidade do uso da taxionomia de Bloom, original ou revisada, como uma teoria útil na efetivação de fóruns de discussão que colaborem para o aprimoramento do ensino e da aprendizagem em cursos on-line.

\section{REFERÊNCIAS}

AZEVEDO, B.F.T.; BEHAR, P.A.; REATEGUI, E.B. Indicadores de relevância para análise de fóruns de discussão. In: SIMPÓSIO BRASILEIRO DE INFORMÁTICA NA EDUCAÇÃO. 23. 2012. Anais.... Disponível em: <http://www.brie.org/pub/index.php/sbie/article/view/1729/1490>. Acesso em 19 jul. 2016.

BAI, H. Facilitating students' critical thinking in online discussion: an instructor's experience. J. Interactive Online Learning, v.8, n.2, p.156-164, 2009.

BARAN, E.; CORREIA, A.P. A Professional development framework for online teaching. In: Tech Trends, v.58, n.5, p.95-101, 2014.

EKAHITANOND, V. Promoting university students' critical thinking skills through peer feedback activity in an online discussion fórum. Alberta J. Educ. Res., v.59, n.2, p.247-265, 2013.

ERTMER, P.A. Using peer feedback to enhance the quality of student online postings: an exploratory study. J. Computer-Mediated Communication, v.12, p.412433, 2007.

FERRAZ, A.P.C.M.; BELHOT, R.V. Taxonomia de Bloom: revisão teórica e apresentação das adequações do instrumento para definição de objetivos instrucionais. Gestão da Produção, v.17, n.2, p.421-431, 2010.

GARRISON, D.R.; ANDERSON, T. E-learning in the 21st century: A Framework for Research and Practice. London: Routledge Falmer, 2003. 
GÓMEZ, A. I. Pérez. Diferentes enfoques para entender o ensino. In: SACRISTÁN, J. Gimeno; GÓMEZ, A. I. Pérez. Compreender e transformar o ensino. Porto Alegre: Artmed, 1998. p. 67-69.

KNOWTON, D.S. Promoting durable knowledge construction through online discussion. In: PROCEEDINGS OF THE ENNUAL MID-SOUTH INSTRUCIONAL TECNOLOGY CONFERENCE. 2001. Anais... Disponível em: <http://files.eric.ed.gov/fulltext/ED463724.pdf>. Acesso em 17 jul. 2016.

KRATHWOHL, D.R. A revision of Bloom's taxonomy: an overview. Theory Into Practice, v.41, n.4, p. 213-218, 2002.

LUHRS, C.; MCANALLY-SALAS, L. Collaboration levels in asynchronous discussion forums: a social network analysis approach. J. Interactive Online Learning, v.14, n.1, p.29-44, 2016.

MARZANO, R.J.; KENDALL, J.S. The new taxonomy of educational objectives. Thousand Oaks: Corwin, 2007.

NUSSBAUM, E.M. et al. Enhancing the quality of on-line discussions. 2002. Disponível em: <http://files.eric.ed.gov/fulltext/ED466767.pdf>. Acesso em: 16 jul. 2016.

PETRESS, K. Critical thinking: na extended definition. 2004. Disponível em: $<$ http://isites.harvard.edu/fs/docs/icb.topic265890.files/Critical_Thinking_File/06_CT_ Extended_Definition.pdf $>$. Acesso em: 20 jul. 2016.

ROCHA, A.L.A.D. A promoção das competências do pensamento crítico nos adultos, através da formação em e-learning. 2011. 149f. Dissertação (Mestrado em Educação) - Universidade de Lisboa. Lisboa, 2011.

SILVA, J.C. Uma análise das interações discentes em fóruns de discussão online de ambientes virtuais de aprendizagem através da análise de redes sociais. 2015. 122f. Dissertação (Mestrado em Informática) - Universidade Federal da Paraíba, João Pessoa. 2015.

SWAN, K. et al. Shaping online discussion: assessment matters. E-Mentor, v.18, n.1, p.1-6, 2007.

VEIGA, E. et al. A perspectiva dos alunos sobre um projeto de desenvolvimento do pensamento crítico no ensino superior. Rev. Lusófona Educ., v.32, n.32, p.109-121, 2016. 